\title{
Study on Capacitance of Zn-Based Electrode in Redox Electrolyte System
}

\author{
Yubin Yang, Xinmei Fan, Shaomin Zhu*, Hongfeng Xu \\ Liaoning Provincial Key Laboratory of New Energy Battery, Dalian Jiaotong University, Dalian, China \\ Email: ^smzhu91@126.com
}

How to cite this paper: Yang, Y.B., Fan, X.M., Zhu, S.M. and Xu, H.F. (2020) Study on Capacitance of $\mathrm{Zn}$-Based Electrode in Redox Electrolyte System. Journal of Materials Science and Chemical Engineering, 8, 35-43.

https://doi.org/10.4236/msce.2020.81004

Received: November 30, 2019

Accepted: January 10, 2020

Published: January 13, 2020

Copyright $\odot 2020$ by author(s) and Scientific Research Publishing Inc. This work is licensed under the Creative Commons Attribution International License (CC BY 4.0).

http://creativecommons.org/licenses/by/4.0/

\begin{abstract}
Electrode material is one of the most important factors affecting the performance of supercapacitors, and electrolyte solution is another. In this work, electrochemical properties of hydroxide zinc carbonate composite electrode $(\mathrm{HZC})$ in $\mathrm{KOH}+\mathrm{K}_{3}\left[\mathrm{Fe}(\mathrm{CN})_{6}\right]$ electrolyte were studied. It was proved that $\left[\mathrm{Fe}(\mathrm{CN})_{6}\right]^{3-}$ in electrolyte participated in electrochemical reactions and promoted electron transfer. The specific capacitance of HZC electrode was as high as $920.5 \mathrm{~F} \cdot \mathrm{g}^{-1}$ at $1.0 \mathrm{~A} \cdot \mathrm{g}^{-1}$ in $1 \mathrm{~mol} \cdot \mathrm{L}^{-1} \mathrm{KOH}$ and $0.04 \mathrm{~mol} \cdot \mathrm{L}^{-1} \mathrm{~K}_{3}\left[\mathrm{Fe}(\mathrm{CN})_{6}\right]$ electrolyte, which is $172.9 \%$ higher than that in $\mathrm{KOH}$. The combination of HZC electrode and low alkalinity aqueous electrolyte provided the supercapacitor system with good capacitance performance, safety, and environmentally friendly.
\end{abstract}

\section{Keywords}

Hydroxide Zinc Carbonate, Supercapacitor, $\left[\mathrm{Fe}(\mathrm{CN})_{6}\right]^{3-}$, Redox Electrolyte

\section{Introduction}

Nowadays, the world is facing a series of challenges related to energy, including energy depletion, environmental pollution, and so on. Researchers are committed to studying green and high-performance energy storage devices to meet the needs of sustainable innovative development [1] [2]. Supercapacitor (SC) is one of the most promising energy storage devices. The electrolytes used in the supercapacitor system are mainly divided into three categories: aqueous phase, organic phase and ionic liquid [3]. Water phase system is the most widely used electrolyte in supercapacitors. However, limited by water decomposition potential, the operating voltage window of capacitors in aqueous solution is generally lower than $1 \mathrm{~V}$ [4]. Organic phase and ionic liquid can achieve higher operating voltage window $(2.2-2.9 \mathrm{~V}$ and $2.6-4 \mathrm{~V})$, which can effectively improve the 
energy density of capacitors, but there are still certain safety and environmental risks [5].

In recent years, redox active additives, or electrically active substances as supplement are introduced in traditional electrolyte systems to improve the performance of SC [6] [7]. In this way, the capacitance can be effectively improved to achieve the energy density close to that of battery [6]. Compared with electrode material synthesis and selection, this method is simpler, safer, low-cost, and non-toxic, which is easy to mass production [7]. Senthilkumar et al. [8] achieved about 2 times higher specific capacitance of carbon electrodes in sol-electrolyte systems containing hydroquinone and potassium iodide. They believed that the increased specific capacitance was due to the rapid Faraday reaction of redox components in the electrolyte solution at the interface between the electrode and electrolyte.

Hydroxide zinc carbonate composite electrode (HZC) has been synthesized in our previous studies, which showed novel electrochemical activity in high concentration $\mathrm{KOH}$ electrolyte [9]. However, higher concentration of $\mathrm{KOH}$ will undoubtedly increase the corrosion of electrodes and equipment, which is unfavorable to the long-term operation and performance of supercapacitors. In this work, $\mathrm{K}_{3}\left[\mathrm{Fe}(\mathrm{CN})_{6}\right]$ redox active components were introduced into low concentration $\mathrm{KOH}$ electrolyte to optimize the system and maintain capacitive performance. The influence of redox component on electrochemical performance of electrode and supercapaictor, and the interaction between active substance and electrolyte were analyzed.

\section{Experimental}

\subsection{Preparation of Working Electrode}

$\mathrm{Zn}\left(\mathrm{NO}_{3}\right)_{2} \cdot 6 \mathrm{H}_{2} \mathrm{O} 0.11 \mathrm{~g}, \mathrm{Al}\left(\mathrm{NO}_{3}\right)_{2} \cdot 6 \mathrm{H}_{2} \mathrm{O} 0.03 \mathrm{~g}$, and $\mathrm{CO}\left(\mathrm{NH}_{2}\right)_{2} 0.14 \mathrm{~g}$ were dissolved in $36 \mathrm{ml}$ deionized water and stirred for $15 \mathrm{~min}$. Then the solution was transferred to $50 \mathrm{ml}$ hydrothermal reactor. After pretreatment, nickel foam was added in above solution and the temperature was maintained at $120^{\circ} \mathrm{C}$ for $4 \mathrm{~h}$. Nickel foam was washed to neutral and dried overnight after the reaction.

Active carbon (AC, BP2000), acetylene black and PTFE mixed together with mass proportion of $8: 1: 1$, using ethanol as dispersant. Paste was stirred and smeared evenly on $1 \times 1 \mathrm{~cm}^{2}$ nickel foam, then dried 6 hours at $80^{\circ} \mathrm{C}$.

\subsection{Characterization}

The morphological studies of HZC were performed using field emission scanning electronic microscope (FESEM, JEOLJEM-6360LV, Japan) with an accelerating voltage of $20-30 \mathrm{kV}$. The sample was processed with gold spraying before testing.

Classic three electrode system was used to electrochemical analysis with $\mathrm{Pt}$ electrode as counter electrode, $\mathrm{HgO} / \mathrm{Hg}$ electrode as reference electrode, $\mathrm{HZC}$ electrode as working electrode, and $1 \mathrm{~mol} \cdot \mathrm{L}^{-1} \mathrm{KOH}$ containing a certain amount 
of $\mathrm{K}_{3}\left[\mathrm{Fe}(\mathrm{CN})_{6}\right]$ as electrolyte.

Electrochemical performance of supercapacitor assembled with HZC electrode and activated carbon electrode was tested on CHI660E electrochemical workstation (China). Cycle stability of SC was tested by LANHE (China). The voltage window is $0-1.6 \mathrm{~V}$.

\section{Results and Discussion}

\subsection{Cyclic Voltammetry Analysis}

Figure 1 shows SEM analysis of HZC material on foam Ni. The morphology of HZC shows regular hexagon nanosheet with about $1 \mu \mathrm{m}$ in diameter and 100 $200 \mathrm{~nm}$ for thickness (measured in FESEM image, 20,000x). All partials constitute a three-dimensional network electrode layer. This special structure provides three-dimensional nucleation site for in-situ growth of electrode active substances.

In three-electrode system, the electrochemical performance of the electrode in the $\mathrm{K}_{3}\left[\mathrm{Fe}(\mathrm{CN})_{6}\right]+\mathrm{KOH}$ electrolyte was tested firstly. The results were analyzed and compared with the cyclic voltammetry (CV) curve of the electrode in 1 $\mathrm{mol} \cdot \mathrm{L}^{-1} \mathrm{KOH}$ electrolyte, as shown in Figure 2.

In $\mathrm{KOH}$ electrolyte, a pair of main redox peaks appeared in $\mathrm{CV}$ curve at about $0.34 \mathrm{~V}$ and $0.56 \mathrm{~V}$ ( vs $\mathrm{HgO} / \mathrm{Hg}$ ) at scanning rate of $0.01 \mathrm{~V} \cdot \mathrm{s}^{-1}$, which could be attributed to the transition between $\mathrm{Zn}$ (II) and $\mathrm{Zn}$ (III) of HZC electrode. The HZC electrode showed typical pseudocapacitance characteristics [10] [11]. In $\mathrm{K}_{3}\left[\mathrm{Fe}(\mathrm{CN})_{6}\right]+\mathrm{KOH}$ electrolyte system, a new oxidation peak appeared in $\mathrm{CV}$ curves at about $0.42 \mathrm{~V}$ (vs $\mathrm{HgO} / \mathrm{Hg}$ ), and the strength of oxidation peaks increased with $\mathrm{K}_{3}\left[\mathrm{Fe}(\mathrm{CN})_{6}\right]$ content in electrolyte. It can be speculated that the

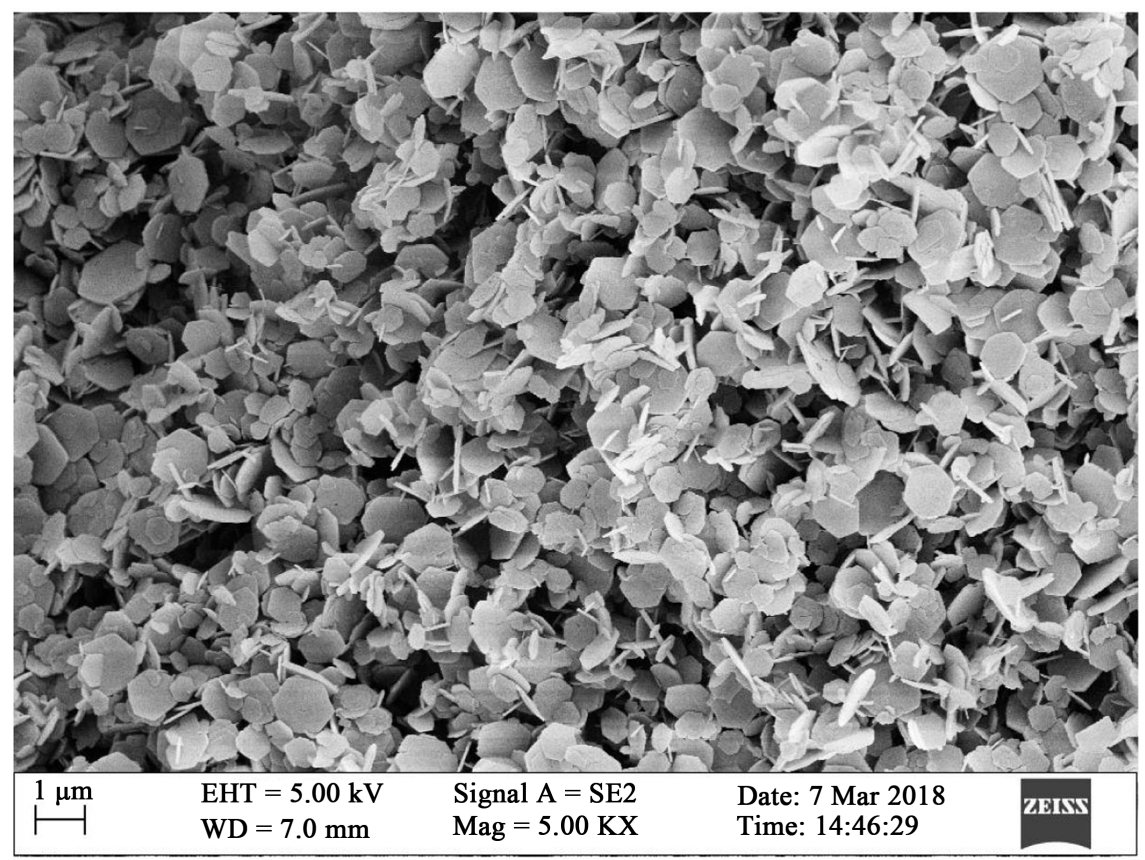

Figure 1. SEM of HZC electrode. 


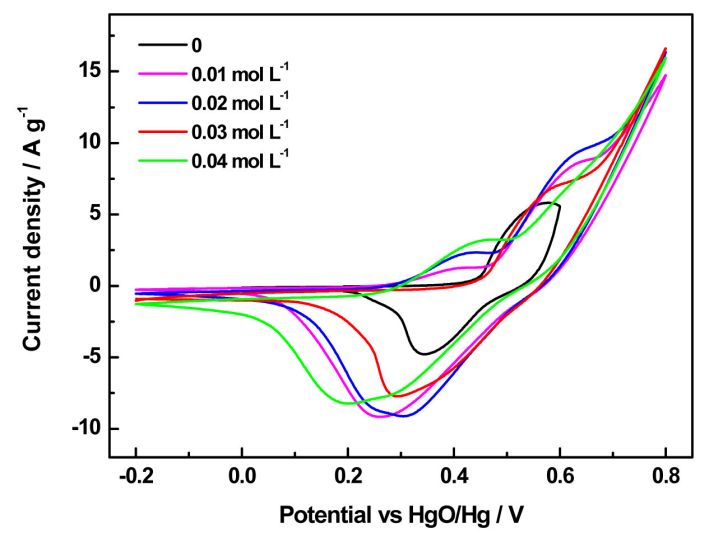

Figure 2. CV curves comparison of electrodes at $0.01 \mathrm{~V} \cdot \mathrm{s}^{-1}$ in $\mathrm{KOH}$ electrolyte with $\mathrm{K}_{3}\left[\mathrm{Fe}(\mathrm{CN})_{6}\right]$.

new redox peak of $\mathrm{CV}$ curve comes from transformation between $\left[\mathrm{Fe}(\mathrm{CN})_{6}\right]^{3-}$ and $\left[\mathrm{Fe}(\mathrm{CN})_{6}\right]^{4-}[3][11]$. Theoretical analysis shows that standard potential of $[\mathrm{Fe}(\mathrm{CN}) 6]^{3-} /\left[\mathrm{Fe}(\mathrm{CN})_{6}\right]^{4-}$ is $0.2577 \mathrm{~V}$ vs. $\mathrm{HgO} / \mathrm{Hg}(0.3557 \mathrm{~V}$ vs. SHE$)$, and the deviation of redox peak may be related to properties of substrate, surface roughness of substrate, or superpotential of electrode [12]. On the other hand, the peak current and peak area of CV curves increased significantly [13], and the peak potential deviated to higher and lower potential respectively in $\mathrm{K}_{3}\left[\mathrm{Fe}(\mathrm{CN})_{6}\right]$ $+\mathrm{KOH}$ electrolyte system. This result indicates that more species are involved in redox process on the electrode surface, which effectively improves the capacitance. Secondly, these changes of strength and position of redox peaks, indicating possible interaction between two electric pairs during charging and discharging [3] [7].

\subsection{Galvanostatic Charge and Discharge Test}

Galvanostatic charge and discharge curves at $1 \mathrm{~A} \cdot \mathrm{g}^{-1}$ are shown in Figure 3. In $\mathrm{KOH}$ electrolyte, there is a charging/discharging platform, while there are two obvious charging/discharging platforms at about 0.4 and $0.5 \mathrm{~V}$ in $\mathrm{K}_{3}\left[\mathrm{Fe}(\mathrm{CN})_{6}\right]+$ $\mathrm{KOH}$ electrolytes, which further confirms existence of multi-step redox process in $\mathrm{K}_{3}\left[\mathrm{Fe}(\mathrm{CN})_{6}\right]+\mathrm{KOH}$ system [10].

On the other hand, in $\mathrm{K}_{3}\left[\mathrm{Fe}(\mathrm{CN})_{6}\right]+\mathrm{KOH}$ electrolyte system, discharging time of electrode is significantly longer than that in $\mathrm{KOH}$ system, especially containing $0.04 \mathrm{~mol} \cdot \mathrm{L}^{-1} \mathrm{~K}_{3}\left[\mathrm{Fe}(\mathrm{CN})_{6}\right]$ in electrolyte.

The specific capacitance of HZC composite electrode can be estimated from the discharge current using following equation [6]:

$$
C=I \times t /(m \times \Delta V)
$$

where, $C\left(\mathrm{~F} \cdot \mathrm{g}^{-1}\right)$ is the specific capacitance of the electrode. $I(\mathrm{~A})$ is charge and discharge current. $t(\mathrm{~s})$ is discharge time and $\Delta V(\mathrm{~V})$ for charging and discharging voltage window, $m(\mathrm{~g})$ as electroactive material quality.

As can be seen in Table 1 , the specific capacitance of electrodes in $\mathrm{K}_{3}\left[\mathrm{Fe}(\mathrm{CN})_{6}\right]$ $+\mathrm{KOH}$ electrolyte system is generally higher than that in $\mathrm{KOH}$. Under the 


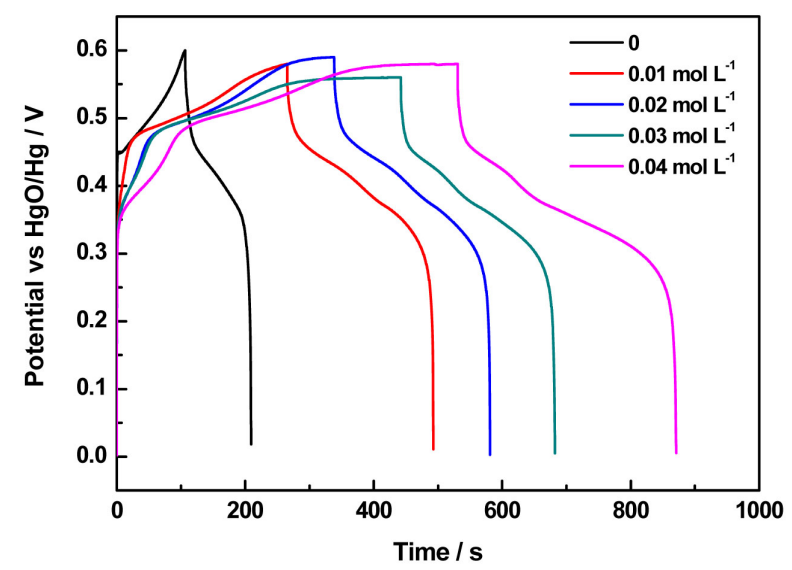

Figure 3. Galvanostatic charge and discharge curves of $\mathrm{HZC}$ electrode in $\mathrm{KOH}$ electrolytes with $\mathrm{K}_{3}\left[\mathrm{Fe}(\mathrm{CN})_{6}\right]$ at $1 \mathrm{~A} \cdot \mathrm{g}^{-1}$.

Table 1. Comparisons of specific capacitance $\left(\mathrm{F} \cdot \mathrm{g}^{-1}\right)$ of HZC electrode in redox electrolytes.

\begin{tabular}{cccccc}
\hline \multirow{2}{*}{ Electrolyte } & \multicolumn{5}{c}{ Current density $\left(\mathrm{A} \cdot \mathrm{g}^{-1}\right)$} \\
\cline { 2 - 6 } & 1 & 2 & 3 & 4 & 5 \\
\hline $1 \mathrm{~mol} \cdot \mathrm{L}^{-1} \mathrm{KOH}$ & 337.3 & 330.1 & 300.5 & & \\
$+0.01 \mathrm{~mol} \cdot \mathrm{L}^{-1} \mathrm{~K}_{3}\left[\mathrm{Fe}(\mathrm{CN})_{6}\right]$ & 672.8 & 400.1 & 270.4 & 353.0 & 293.9 \\
$+0.02 \mathrm{~mol} \cdot \mathrm{L}^{-1} \mathrm{~K}_{3}\left[\mathrm{Fe}(\mathrm{CN})_{6}\right]$ & 678.6 & 586.1 & 488.4 & 416.8 & 334.7 \\
$+0.03 \mathrm{~mol} \cdot \mathrm{L}^{-1} \mathrm{~K}_{3}\left[\mathrm{Fe}(\mathrm{CN})_{6}\right]$ & 691.2 & 513.8 & 374.9 & 270.8 & 129.8 \\
$+0.04 \mathrm{~mol} \cdot \mathrm{L}^{-1} \mathrm{~K}_{3}\left[\mathrm{Fe}(\mathrm{CN})_{6}\right]$ & 920.5 & 721.9 & 530.8 & 397.4 & 264.3 \\
\hline
\end{tabular}

same current density, the electrode capacitance shows an overall increasing tendency with increase of $\mathrm{K}_{3}\left[\mathrm{Fe}(\mathrm{CN})_{6}\right]$ concentration in electrolyte solution. For example, when the current density is $1 \mathrm{~A} \cdot \mathrm{g}^{-1}$, the specific capacitance of HZC electrode is $337.3 \mathrm{~F} \cdot \mathrm{g}^{-1}$ in the $1 \mathrm{~mol} \cdot \mathrm{L}^{-1} \mathrm{KOH}$, while they are $672.8,678.6,691.2$ and $920.5 \mathrm{~F} \cdot \mathrm{g}^{-1}$, respectively when $\mathrm{K}_{3}\left[\mathrm{Fe}(\mathrm{CN})_{6}\right]$ from 0.01 to $0.04 \mathrm{~mol} \cdot \mathrm{L}^{-1}$ in electrolyte, which is $99.5 \%, 101.2 \%, 104.9 \%$ and $172.9 \%$ higher. It indicates that presence of $\left[\mathrm{Fe}(\mathrm{CN})_{6}\right]^{3-}$ ions significantly improves electrochemical performance of HZC electrode.

Lots of research results show that redox components or media in electrolyte solution can directly participate in electron transfer in redox reaction on electrode surface [14]. Electrochemical performance of electrode can be improved through contribution of pseudocapacitance at electrode-electrolyte interface. Su et al. [14] proposed a mechanism of "Electron Shuttle" when studying electrochemical performance of Co-Al double layered hydroxide electrodes. Researchers believe that electron transmission of $\mathrm{Co}$ (II) is key to determine the reaction rate of whole electrode process. It is considered that addition of $\mathrm{K}_{3}\left[\mathrm{Fe}(\mathrm{CN})_{6}\right]$ or $\mathrm{K}_{4}\left[\mathrm{Fe}(\mathrm{CN})_{6}\right]$ in $\mathrm{KOH}$ promotes the oxidation and electron loss of $\mathrm{Co}(\mathrm{II})$ effectively. According to literature reports and our results in this experiment, we believe that the mechanism of "Electron Shuttle" is also suitable for electrochemical reactions on the surface of HZC electrode. 
As shown in Figure 4, $\mathrm{Zn}$ (II) loses an electron and is oxidized to $\mathrm{Zn}$ (III) during charging process, while $\left[\mathrm{Fe}(\mathrm{CN})_{6}\right]^{3-}$ obtains electron and converts to $\left[\mathrm{Fe}(\mathrm{CN})_{6}\right]^{4-}$. Similarly, during discharge, $\left[\mathrm{Fe}(\mathrm{CN})_{6}\right]^{4-}$ gives one electron to $\left[\mathrm{Fe}(\mathrm{CN})_{6}\right]^{3-}$, and electron is transferred to $\mathrm{Zn}(\mathrm{III})$, which gets the electron and converts to $\mathrm{Zn}(\mathrm{II})$.

Electrode surface reaction equation can be expressed as follows:

$$
\begin{gathered}
\text { Charge }: \mathrm{Zn}(\mathrm{II}) \rightarrow \mathrm{Zn}(\mathrm{III})+\mathrm{e} \\
{\left[\mathrm{Fe}(\mathrm{CN})_{6}\right]^{3-}+\mathrm{e} \rightarrow\left[\mathrm{Fe}(\mathrm{CN})_{6}\right]^{4-}} \\
\text { Discharge }:\left[\mathrm{Fe}(\mathrm{CN})_{6}\right]^{4-} \rightarrow\left[\mathrm{Fe}(\mathrm{CN})_{6}\right]^{3-}+\mathrm{e} \\
\mathrm{Zn}(\mathrm{III})+\mathrm{e} \rightarrow \mathrm{Zn}(\mathrm{II})
\end{gathered}
$$

According to mechanism analysis of charge and discharge process on the electrode surface, redox component in electrolyte can effectively promote electron transfer and reduce charge transfer resistance. Consumption of electrons in Equation (3) also promotes oxidation reaction of $\mathrm{Zn}(\mathrm{II})$ (Equation (2)), making more $\mathrm{Zn}(\mathrm{II})$ on electrode surface become active center and participate in electrode reaction, thereby improving the utilization rate of $\mathrm{Zn}(\mathrm{II})$ and increasing the capacitance performance of electrode. Redox components, on the other hand, store charge and energy synchronously through their conversion between multi-valent species, providing additional capacitance to the electrode.

\subsection{Asymmetric Supercapacitor Performance}

Electrochemical performance of AC electrode in $\mathrm{K}_{3}\left[\mathrm{Fe}(\mathrm{CN})_{6}\right]+\mathrm{KOH}$ electrolyte is studied, and the activity is compared with that in $\mathrm{KOH}$, as shown in Figure 5. It can be seen that $\mathrm{CV}$ curve of $\mathrm{AC}$ presents a typical rectangular shape, which is similar to that in $\mathrm{KOH}$, indicating that $\mathrm{AC}$ electrode still exhibits relatively ideal double layer capacitance characteristics in $\mathrm{K}_{3}\left[\mathrm{Fe}(\mathrm{CN})_{6}\right]+\mathrm{KOH}$. No significant redox peak of $\left[\mathrm{Fe}(\mathrm{CN})_{6}\right]^{3-}$ is observed in CV curve. It is worth noting that closed area of $\mathrm{CV}$ curve for $\mathrm{AC}$ in $\mathrm{K}_{3}\left[\mathrm{Fe}(\mathrm{CN})_{6}\right]+\mathrm{KOH}$ is nearly 1 time larger than that in $\mathrm{KOH}$, which indicates that $\mathrm{AC}$ electrode presents higher specific capacitance in mixed electrolyte solution. In addition, compared with $\mathrm{CV}$ curve in $\mathrm{KOH}, \mathrm{CV}$ curve of AC electrode in $\mathrm{K}_{3}\left[\mathrm{Fe}(\mathrm{CN})_{6}\right]+\mathrm{KOH}$ is significantly shifted downward, showing decreased charge current and increased discharge current. It can be speculated that $\left[\mathrm{Fe}(\mathrm{CN})_{6}\right]^{3-}$ exerts strong gravitation on $\mathrm{K}^{+}$in mixed electrolyte,
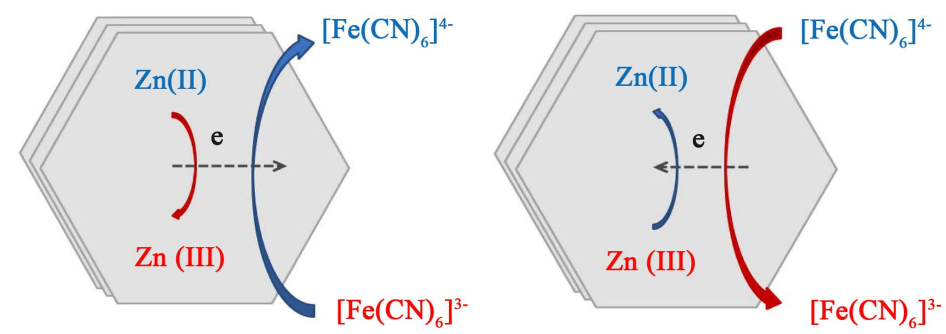

Figure 4. Schematic of charge and discharge process on HZC electrode in $\mathrm{K}_{3}\left[\mathrm{Fe}(\mathrm{CN})_{6}\right]+$ $\mathrm{KOH}$ electrolyte. 
causing some $\mathrm{K}^{+}$ions form ion layer around $\left[\mathrm{Fe}(\mathrm{CN})_{6}\right]^{3-}$ ions, which reduces migration ability of $\mathrm{K}^{+}$in solution. During charging process, $\mathrm{K}^{+}$in solution migrates to the surface of AC electrode. Under external electric field and $\left[\mathrm{Fe}(\mathrm{CN})_{6}\right]^{3-}$ ions electric field competition, it is possible that not all $\mathrm{K}^{+}$can escape from gravity of $\left[\mathrm{Fe}(\mathrm{CN})_{6}\right]^{3-}$ ions electric field. So, part of $\mathrm{K}^{+}$ions migrate to AC electrode and participate in formation of double electric layer. At the same time, some $\mathrm{K}^{+}$ may exist in loose layers outside the double electric layer of AC electrode, so as to form small charging current. During discharge process, external electric field disappears. $\mathrm{K}^{+}$ions in double electric layer and loose layer outside the double electric layer migrate under electrostatic gravity and $\left[\mathrm{Fe}(\mathrm{CN})_{6}\right]^{3-}$ ion electric field, which effectively improves discharge capacity.

Figure 5 shows CV curves of AC and HZC electrodes in three electrode system, where $\mathrm{K}_{3}\left[\mathrm{Fe}(\mathrm{CN})_{6}\right]+\mathrm{KOH}$ as electrolyte. According to the charge conservation principle, it can be obtained that the mass ratio of $\mathrm{HZC}$ and $\mathrm{AC}$ materials is about 1.5:1.

Electrochemical performance of the assembled asymmetric supercapacitor $\mathrm{HZC} / / \mathrm{AC}$ was tested and compared (Figure 6). It can be seen that current density

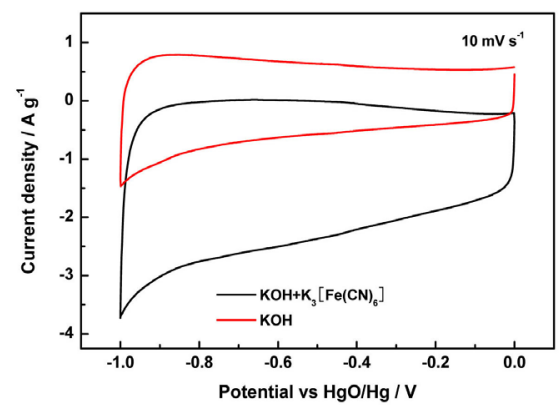

(a)

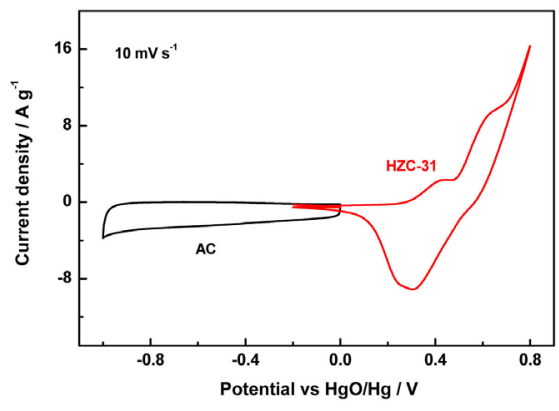

(b)

Figure 5. (a) CV curves of $\mathrm{AC}$ electrode in $\mathrm{K}_{3}\left[\mathrm{Fe}(\mathrm{CN})_{6}\right]+\mathrm{KOH}$ solution, (b) CV curves of $\mathrm{AC}$ and HZC electrodes performed in three-electrode system.

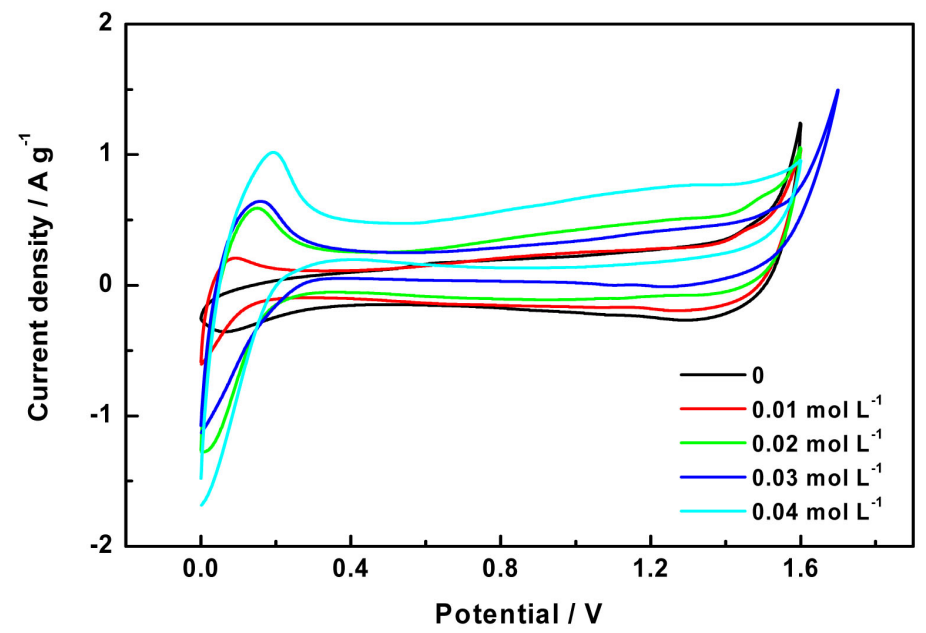

Figure 6. CV curves of HZC//AC asymmetric supercapacitors with different amount of $\mathrm{K}_{3}\left[\mathrm{Fe}(\mathrm{CN})_{6}\right]$ in electrolyte. 
in $\mathrm{CV}$ curves increases with $\mathrm{K}_{3}\left[\mathrm{Fe}(\mathrm{CN})_{6}\right]$ content in electrolyte at $10 \mathrm{mV} \cdot \mathrm{s}^{-1}$. Compared with the result in $\mathrm{KOH}$ electrolyte, the response current in $\mathrm{K}_{3}\left[\mathrm{Fe}(\mathrm{CN})_{6}\right]$ $+\mathrm{KOH}$ electrolyte showed significant changes at range of $0-0.2 \mathrm{~V}$, and peak current increases with $\mathrm{K}_{3}\left[\mathrm{Fe}(\mathrm{CN})_{6}\right]$ content in electrolyte. Based on these results, it is speculated that the excellent performance of SC comes from the pseudo-capacitance behavior of redox electrolyte components and additional double electric layer effect of redox electrolyte components on AC electrode [15]. $\mathrm{K}_{3}\left[\mathrm{Fe}(\mathrm{CN})_{6}\right]$ in electrolyte improves electrochemical performance of two electrodes at the same time, thereby improving the capacitance of asymmetric chemical capacitors.

\section{Conclusion}

Electrochemical performance of $\mathrm{HZC}$ electrode was measured in redox electrolyte system composed of $\mathrm{KOH}$ and $\mathrm{K}_{3}\left[\mathrm{Fe}(\mathrm{CN})_{6}\right]$. $\left[\mathrm{Fe}(\mathrm{CN})_{6}\right]^{3-}$ improved capacitance performance of electrodes through participation and synergistic action. Redox component $\mathrm{K}_{3}\left[\mathrm{Fe}(\mathrm{CN})_{6}\right]$ in electrolyte can promote electron transfer effectively. The results show that specific capacitance of $\mathrm{HZC}$ electrode in $\mathrm{KOH}+$ $\mathrm{K}_{3}\left[\mathrm{Fe}(\mathrm{CN})_{6}\right]$ increases to $920.5 \mathrm{~F} \cdot \mathrm{g}^{-1}$ at $1.0 \mathrm{~A} \cdot \mathrm{g}^{-1}$, which is much higher than that in $\mathrm{KOH}$. Combination of $\mathrm{Zn}$-based electrode and low alkalinity electrolyte achieved SC equipment good performance and friendly environment. Next works will focus on electrolyte composition and stability optimization.

\section{Conflicts of Interest}

The authors declare no conflicts of interest regarding the publication of this paper.

\section{References}

[1] Grillo, G., Han, W., Kong, L.B., Liu, M.C., Wang, D., Li, J.J. and Kang, L. (2015) A High Performance Redox-Mediated Electrolyte for Improving Properties of Metal Oxides Based Pseudocapacitive Materials. Electrochimica Acta, 186, 478-485. https://doi.org/10.1016/j.electacta.2015.10.161

[2] Qu, Q.T., Wang, B., Yang, L.C., Shi, Y., Tian, S. and Wu, Y.P. (2008) Study on Electrochemical Performance of Activated Carbon in Aqueous $\mathrm{Li}_{2} \mathrm{SO}_{4}, \mathrm{Na}_{2} \mathrm{SO}_{4}$ and $\mathrm{K}_{2} \mathrm{SO}_{4}$ Electrolytes. Electrochemistry Communications, 10, 1652-1655. https://doi.org/10.1016/j.elecom.2008.08.020

[3] Senthilkumar, S.T., Selvan, R.K. and Melo, J.S. (2013) Redox Additive/Active Electrolytes: A Novel Approach to Enhance the Performance of Supercapacitors. Journal of Materials Chemistry $A, 1,12386-12394$.

https://doi.org/10.1039/c3ta11959a

[4] Wang, G., Zhang, L. and Zhang, J. (2012) A Review of Electrode Materials for Electrochemical Supercapacitors. Chemical Society Reviews, 41, 797-828. https://doi.org/10.1039/C1CS15060J

[5] Wang, H., Li, Z., Jin, K.T., Holt, C.M.B. Tan, X., Xu, Z., Amirkhiz, B.S., Harfield, D., Anyia, A. and Stephenson, T. (2013) Supercapacitors Based on Carbons with Tuned Porosity Derived from Paper Pulp Mill Sludge Biowaste. Carbon, 57, 317-328. 
https://doi.org/10.1016/j.carbon.2013.01.079

[6] Singh, A., Akhtar, M.A. and Chandra, A. (2017) Trade-off between Capacitance and Cycling at Elevated Temperatures in Redox Additive Aqueous Electrolyte Based High Performance Asymmetric Supercapacitors. Electrochimica Acta, 229, 291-298. https://doi.org/10.1016/j.electacta.2017.01.167

[7] Mai, L.Q., Minhas-Khan, A., Tian, X., Hercule, K.M., Zhao, Y.L., Lin, X. and Xu, X. (2013) Synergistic Interaction between Redox-Active Electrolyte and Binder-Free Functionalized Carbon for Ultrahigh Supercapacitor Performance. Nature Communications, 4, 2923. https://doi.org/10.1038/ncomms3923

[8] Senthilkumar, S.T., Selvan, R.K., Lee, Y.S. and Melo, J.S. (2013) Electric Double Layer Capacitor and Its Improved Specific Capacitance Using Redox Additive Electrolyte. Journal of Materials Chemistry A, 1, 1086-1095.

https://pubs.rsc.org/en/content/articlelanding/2013/ta/c2ta00210h/unauth\#!divAbst $\underline{\text { ract }}$

https://doi.org/10.1039/C2TA00210H

[9] Zhao, Y., Yang, Y.B. and Ren, R.M. (2019) High Performance Hydroxide Zinc Carbonate Composite for Supercapacitors. Journal of Materials Science and Chemical Engineering, 7, 54-60. https://doi.org/10.4236/msce.2019.711006

[10] Liu, X., Yang, Y., Xing, X., Zou, T., Wang, Z. and Wang, Y. (2017) From Water and $\mathrm{Ni}$ Foam to a Ni(OH)$)_{2} @ N i$ Foam Binder-Free Supercapacitor Electrode: A Green Corrosion Route. ChemElectroChem, 5, 434-444. https://doi.org/10.1002/celc.201701094

[11] Zheng, X., Han, Z., Yao, S., Xiao, H., Chai, F., Qu, F. and Wu, X. (2016) Spinous $\alpha-\mathrm{Fe}_{2} \mathrm{O}_{3}$ Hierarchical Structures Anchored on Ni Foam for Supercapacitor Electrodes and Visible Light Driven Photocatalysts. Dalton Transactions, 45, 7094-7103. https://pubs.rsc.org/en/content/articlelanding/2016/DT/C6DT00002A\#!divAbstract https://doi.org/10.1039/C6DT00002A

[12] Su, L., Zhang, X., Yuan, C. and Gao, B. (2008) Symmetric Self-Hybrid Supercapacitor Consisting of Multiwall Carbon Nanotubes and Co-Al Layered Double Hydroxides. Journal of the Electrochemical Society, 155, A110-A114. https://doi.org/10.1149/1.2806844

[13] Su, L., Gong, L., Lü, H. and Qiang, X. (2014) Enhanced Low-Temperature Capacitance of $\mathrm{MnO}_{2}$ Nanorods in a Redox-Active Electrolyte. Journal of Power Sources, 248, 212-217. https://doi.org/10.1016/j.jpowsour.2013.09.047

[14] Su, L.H., Zhang, X.G., Mi, C.H., Gao, B. and Liu, Y. (2009) Improvement of the Capacitive Performances for Co-Al Layered Double Hydroxide by Adding Hexacyanoferrate into the Electrolyte. Physical Chemistry Chemical Physics, 11, 2195-2202. https://doi.org/10.1039/b814844a

[15] Abdelkader, A.M., Vallés, C., Cooper, A.J., Kinloch, I.A. and Dryfe, R.A. (2014) Alkali Reduction of Graphene Oxide in Molten Halide Salts: Production of Corrugated Graphene Derivatives for High-performance Supercapacitors. ACS Nano, 8, 11225-11233. https://doi.org/10.1021/nn505700x 